\section{Antimicrobial resistance pattern of Escherichia coli strains isolated from poultry farmers and poultry slaughterers in Morocco}

\section{Abstract}

Aim: The objective of this study is to characterize the antibiotic resistance pattern of Escherichia coli isolates from the fecal samples of poultry workers (farmers and slaughterers), and to study the possible dissemination of resistant $E$. coli from poultry to humans.

Methods: Sixty-four E. coli strains isolated from the fecal samples of poultry workers (33 from poultry farmers and 31 from poultry slaughterers) and 35 isolates from a control group workers were tested for antibiotic resistance by agar disk diffusion with 11 antimicrobial agents.

Results: Resistance of $E$. coli isolated from poultry workers to tetracycline, ampicillin and norfloxacin were significantly $(p<0.05)$ higher than those isolated from the control group. All $E$. coli isolates were susceptible to cefotaxime, and most of them are susceptible to gentamicin, amikacin, cefoxitin and ertapenem. Multidrug resistance is alarmingly high in all groups, but was highest in poultry farmers isolates (84\%) and poultry slaughterers isolates (80\%). Approximately $25 \%$ of the $E$. coli isolates from poultry workers showed resistance to four or more antibiotics.

Conclusion: This study suggests that occupational exposure to antimicrobial-resistant $E$. coli through animal contact in the broiler chicken industry may be an important route of entry antimicrobial-resistant $E$. coli into the community.

Keywords

Escherichia Coli; Poultry Workers; Antibiotic Resistance; Multidrug Resistance; Morocco
Abdellah Chaiba ${ }^{1,2}$ Fouzia Rhazi Filali ${ }^{1}$

1 Microbiology and Health Team, Department of Biology, Laboratory of Chemistry-Biology Applied to the Environment, Faculty of Sciences, Moulay Ismail University, Meknès, Morocco.

2 Centre Régional des Métiers de I'Education et de la Formation (CRMEF), Draa Tafilalt, Morocco.

Contact information:

Abdellah Chaiba.

”abchaiba@yahoo.fr 


\section{Introduction}

Antibiotic resistance has been emerged as one of the world's most important public health problems $[1,2]$.Use of antibiotics in human and animal medicine, especially their misuse, has been associated with the selection and spread of antibiotic resistant strains in human beings and animals [3, 4].This acquired resistance occurs not only in pathogenic bacteria but also in the endogenous flora of exposed individuals or populations [5]. Antibiotics are used in animals as well as in humans for both prevention and treatment of infections. In animal husbandry they are also used as growth-promoting agents mixed with feed. These agents are widely used in the poultry industry of Morocco. A recent survey conducted by El-Youbi et al. [6] reported that all private veterinarians in Eastern Morocco have found abusive practices of using avian antibiotics.

Fecal flora of poultry contains a relatively high proportion of resistant bacteria; this is due to the high antibiotic selection pressure on bacterial flora of these birds [7]. During the slaughtering process of poultry birds, there can be occurring of fecal contamination through the guts of these birds with multiresistant bacteria especially $E$. coli $[8,9]$. The human intestinal tract is the ideal place where antibiotic resistant bacteria can transfer their resistance genes to the endogenous human flora [10].

Many studies have shown that intestinal tract of human volunteers were colonized with resistant $E$. coli originated from poultry [11, 12]. Other investigations have revealed that farm animals are a potential reservoir of antibiotic resistant bacteria [13, 14]. In contrast, some authors [15, 16, 17] have reported that the antibiotic resistance transfer between animals and humans was limited because animal strains colonizing the alimentary tract less readily than human ones. However, the actual impact of antibiotic resistance bacteria isolated from workers who are in frequent contact with animals is not well known.
This study aimed to investigate and compare the antibiotic resistance profiles of $E$. coli isolates from poultry workers of both farmers and slaughterers and a control group of healthy individuals living in the same region.

\section{Materials and Methods}

\section{Collection of fecal samples}

Our study was carried out from January through April 2016, in Ouarzazate -Morocco. We collected fecal samples from healthy persons. A total of 33 samples from poultry farmers and 31 from poultry slaughterers. For the comparison, 35 fecal samples were collected from the same area from healthy persons who are practicing other professions except healthcare workers. To avoid cross-risk factors, we have excluded people who had been hospitalized within the last six months and people who received antibiotic treatment a month prior to be included in this study.

\section{Antibiotic susceptibility testing}

The isolation and purification of $E$. coli strains was made on MacConkey agar and the identification was performed using API20E system (Biomerieux, Marcy l'Etoile, France). The isolates were screened for their antibiotic resistance to the following antibiotics (Marnes-La-Coquette, France): Amoxicillinclavulanic acid (AMC ) 20+10 $\mu$; cefoxitin FOX 30 $\mu \mathrm{g}$; cefotaxime CTX $30 \mu \mathrm{g}$; tetracycline TE $30 \mathrm{UI}$; gentamicin (CN) $15 \mu$; amikacin AK $30 \mu$; ertapenem (ETP) $10 \mu \mathrm{g}$; cephalothin (KF) $30 \mu$; ampicillin (AM) $10 \mu \mathrm{g}$; trimethoprim/sulphamethoxazole (SXT) 1.25/23.75 $\mu \mathrm{g}$ and norfloxacin (NOR) 5 $\mu \mathrm{g}$. The antibiogram was performed by the agar diffusion method following the guidelines of the Antibiogram Committee of the French Microbiology Society (CA/SFM, 2014) [18]. Quality control was carried out using E. coli strain ATCC 25922. For each individual samples, one $E$. coli isolate was 
selected randomly for the purpose of testing its antibiotic susceptibility.

\section{Statistical analysis}

The antimicrobial susceptibility data are expressed as percentages or frequency of the human isolates. The $\chi^{2}$ (khi-deux) test was used to estimate overall difference between the percentages of resistance between $E$. coli isolates from different groups. In all cases, $p<0.05$ was regarded as statistically significant.

\section{Results}

A total of 99 fecal samples were examined. Response rates to participate in the study was in poultry farmers and poultry slaughterers were $73.3 \%$ and $68.8 \%$, respectively. Antibiotic resistance rates among $E$. coli isolates found in each group were shown in Table 1. Of the three examined population groups, the highest rate of resistance to almost all tested drugs was detected infecal samples of poultry farmers, followed by those from poultry slaughterers and much lower in the control group, respectively. However, this high rate of resistance was only significant for tetracycline, ampicillin and norfloxacin $(p<0.05)$, and most of the tested isolates showed high antimicrobial resistant to tetracycline .

All $E$. coli isolates were susceptible to CTX, and most of them are susceptible to CN, AK, FOX and ETP. However, one isolate (3\%) from poultry workers showed resistance to cefoxitin and ertapenem, and one isolate (3\%) from poultry farmers were additionally resistant to gentamicin and amikacin. The percentage of multiple drug resistance patterns in $E$. coli isolates of each group is shown in Figure 1.

Multidrug resistance (MDR) was defined in this study as resistance to at least one agent out three or more antimicrobial classes [19]. The highest rate of multidrug resistance $(72.7 \%)$ was found in poul-
Table 1. Comparison of antibiotic resistance rates of E. coli isolates from poultry farmers, poultry slaughterers and control group.

\begin{tabular}{|c|c|c|c|}
\hline \multirow{4}{*}{$\begin{array}{l}\text { Antimicrobial } \\
\text { agents }\end{array}$} & \multirow{2}{*}{\multicolumn{3}{|c|}{$\begin{array}{c}\text { Antibiotic resistance of isolates } \\
\%\end{array}$}} \\
\hline & & & \\
\hline & $\begin{array}{l}\text { Poultry } \\
\text { farmers }\end{array}$ & $\begin{array}{c}\text { Poultry } \\
\text { slaughterers }\end{array}$ & $\begin{array}{l}\text { Control } \\
\text { groups }\end{array}$ \\
\hline & $n=33$ & $n=31$ & $n=35$ \\
\hline $\begin{array}{l}\text { Amoxicillin-clavulanic } \\
\text { acid (AMC 20+10 } \mu \mathrm{g})\end{array}$ & $42.42^{a *}$ & $38.7^{a}$ & $31.42^{a}$ \\
\hline 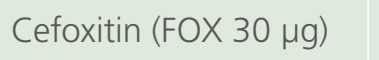 & $3.03^{a}$ & $3.22^{a}$ & $0^{a}$ \\
\hline Cefotaxime (CTX $30 \mu \mathrm{g})$ & $0^{a}$ & $0^{a}$ & $0^{a}$ \\
\hline Tetracycline (TE 30 UI) & $93.93 a$ & $93.54^{a}$ & 71.42 \\
\hline Gentamicin (CN $15 \mu \mathrm{g})$ & $3.03^{a}$ & $0^{a}$ & $0^{a}$ \\
\hline Amikacin (AK $30 \mu \mathrm{g})$ & $3.03^{a}$ & $0^{a}$ & $0^{a}$ \\
\hline Ertapenem (ETP $10 \mu \mathrm{g})$ & $3.03^{a}$ & $3.22^{\mathrm{a}}$ & $0^{a}$ \\
\hline 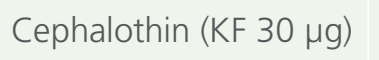 & $36.36^{a}$ & $25.80^{a}$ & $20^{a}$ \\
\hline Ampicillin (AM 10 g) & $45.45^{a}$ & $38^{a}$ & 14.28 \\
\hline $\begin{array}{l}\text { Trimethoprim/ } \\
\text { sulphamethoxazole } \\
\text { (SXT) }\end{array}$ & $39.39^{a}$ & $32.25^{\mathrm{a}}$ & $25.71^{a}$ \\
\hline Norfloxacin (NOR $5 \mu \mathrm{g})$ & $27.27^{a}$ & $25.80^{a}$ & 5.71 \\
\hline *: & Rates are & t significant & $>0.05)$ \\
\hline
\end{tabular}

Figure 1: Antibiotic multiresistance patterns of E. coli strain in poultry farmers, poultry slaughterers and control group.

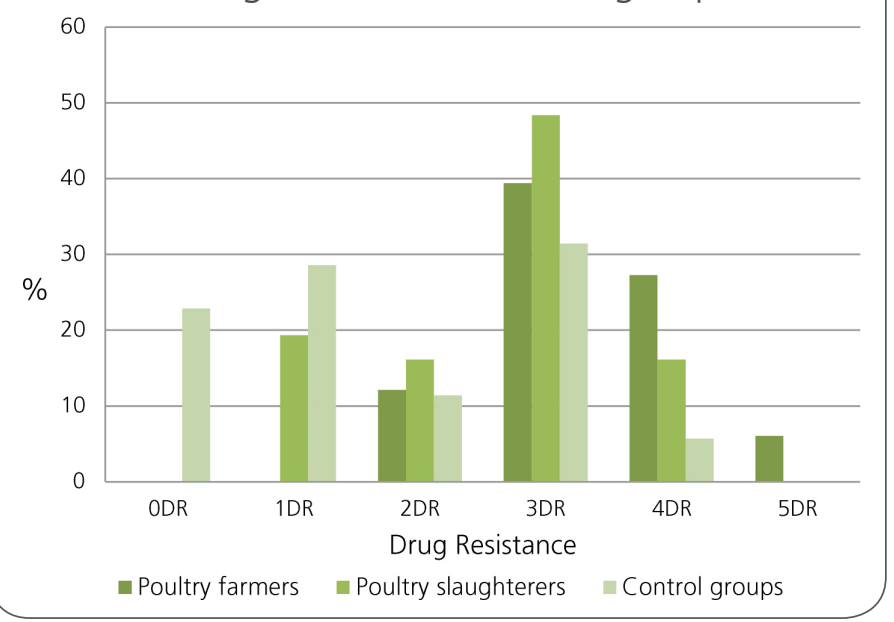


try farmers isolates, followed by those from poultry slaughterers (64.5\%) and significantly lower in the control group (37.1\%). Approximately $25 \%$ of the isolates of poultry workers harboured $E$. coli strains resistant to four or more antibiotics.

The antibiotic resistance pattern most frequently observed was resistance to TE/AM/SXT (12.1\%) in the poultry farmers and (9.7\%) in the poultry slaughterers. The highest number of resistance antibiotic markers was five (TE/AM/AK/CN/NOR) and (TE/AM/SXT/AMC/NOR), in two E. coli isolates from poultry farmers, respectively.

\section{Discussion}

To the best of our knowledge, this is the first based study in Morocco investigated the prevalence of antimicrobial resistant $E$. coli from poultry workers. Our data showed that resistance rates remained significantly higher in E. coli isolated from poultry workers than those from control groups. The results presented here confirm similar studies from other countries showing that poultry farmers and poultry slaughterers workers were at higher risk for colonization with antimicrobial-resistant $E$. coli [10].

The presence and frequency of tetracycline resistant in $E$. coli in this study agree with findings of other studies on antibiotic resistance in $E$. coli $[14,15]$. Tetracycline is a commonly used as first line antibiotic for many domestic animals and as a growth promoter or as an infection control agent, and is often used before the antibiotic resistance profile of a pathogen has been determined [20, 21].

In Morocco, the tetracycline is one of the most prescribed antibiotic in avian medicine [6]. In addition, other studies by us [22] reported that resistance in E. coli strains of poultry meat is higher to tetracycline (80\%) than to trimethoprim/sulphamethoxazole (33.3\%), nalidixic acid (26.6\%) and amoxicillin (20\%). Lower resistance rates were found by EL Al- laoui et al. (5 to 12.5\%) for ertapenem, aztreonam and gentamicin [23]. These results suggest that the extent of antibiotic resistance is associated with the extensive of its usage. Bacterial resistance to tetracycline is plasmid mediated with a wide variety of genetic determinants[22].

According to Van den Bogaard [24], dissemination of resistant bacteria and/or their resistance plasmids from broilers to poultry workers is the most likely explanation for the high antimicrobial resistance rates observed among fecal $E$. coli of the farmers and slaughterers.

The major factor for selecting antimicrobial resistance in bacteria is the misuse of antibiotic, in addition to crowding and poor sanitation in poultry farmes. These three factors are typically related to intensive poultry farming, and explain the high prevalence of resistance in fecal $E$. coli of poultry workers in this and other studies [1].

In this study, carriage of multidrug-resistant E. coli was found significantly more common in poultry workers. Such high rate of multidrug resistance may apparently be occurred due to indiscriminate usage of antimicrobial agents [1]. During slaughtering process multidrug resistant $E$. coli strains can be transferred often from the gut of poultry carcasses and contaminate its meat $[8,24]$.

The findings of our study confirm the effect of exposure to antibiotic resistance bacteria at the work place. This can be also associated with transfer of multiple antimicrobial resistance to commonly used drugs in the poultry farming. Bongers et al. [25] noted a significantly higher rates of $E$. coli resistant isolates to oxytetracycline and ampicillin in poultry industry workers than those not working with birds [26].

\section{Conclusion}

The data obtained in this study indicate that occupational exposure to antimicrobial-resistant $E$. coli from animal contact in the broiler chicken 
industry may be an important route of entry of antimicrobial-resistant $E$. coli into the community. We recommend to establish a strategy which can slow down the spread of antibiotic resistant bacterial strains by applying different preventive measures, such as control of antibiotic use, training and education of workers to practice safety measurements.

\section{References}

1. Van den Bogaard $A E$, Stobberingh EE. Antibiotic usage in animals : impact on bacterial resistance and public health. Drugs 1999 ; 58(4): 589-607.

2. Witte W. Medical consequences of antibiotic use in agriculture. Science 1998; 279: 996-997.

3. Berge AC, Moore D A, Sicho WM. Field trial evaluating the influence of prophylactic and therapeutic antimicrobial administration on antimicrobial resistance of fecal Escherichia coli in dairy calves. Appl Environ Microbiol 2006; 72 : 38723878.

4. Jensen V F, Jakobesen L, Emborg HP, Seyfarth AM, Hammerum AM. Correlation between apramycin and gentamicin use in pigs and an increasing reservoir of gentamicin-resistant Escherichia coli. J Antimicrob Chemother 2006; 58 : 101-107.

5. Cho SH, Lim YS, Kang YH. Comparison of antimicrobial resistance in Escherichia coli strains isolated from healthy poultry and swine farm workers using antibiotics in Korea. Osong Pub Health Res Persp 2012; 3(3):151-155.

6. El-Youbi M., Belbachir C, Monir A; Saalaoui E. Antibiotics in broiler: exhaustive survey among private veterinarians in eastern Morocco. Moroccan J Biology 2016; 13: 60-68.

7. Van den Bogaard AE. Antimicrobial resistance - relation to human and animal exposure to antibiotics. I Antimicrob Chemother 1997; 40:453-454.

8. Caudry SD, Stanisich VA. Incidence of antibiotic resistant Escherichia coli associated with frozen chicken carcasses and characterization of conjugative R-plasmids derived from such strains. Antimicrob Agents Chemother 1979; 16 :701-709.

9. Nazer AH. Transmissible drug resistance in Escherichia coli isolated from poultry and their carcasses in Iran. Cornell Vet 1980; $70: 365-371$.

10. Van den Bogaard AE, London N, Driessen C, Stobberingh EE. Antibiotic resistance of faecal Escherichia coli in poultry, poultry farmers and poultry slaughterers. J Antimicrob Chemother 2001; 47(6):763 -71.
11. Graham JP, Boland JJ, Silbergeld E. Growth promoting antibiotics in food animal production. Public Health Rep 2007; 122:79-87.

12. Teuber M. Veterinary use and antibiotic resistance. Curr Opin Microbiol 2001; 4(5):493 - 499.

13. Cooke EM, Breaden AL, Shooter RA, O'Farrell SM. Antibiotic sensitivity of Escherichia coli isolated from animals, food, hospital patients, and normal people. Lancet ii 1971; 3; 2(7714): 8-10.

14. Levy SB, FitzGerald GB, Macone AB. Spread of antibioticresistant plasmids from chicken to chicken and from chicken to man. Nature 1976; 260:40-2.

15. Caya F, Fairbrother JM, Lessard L, Quessy S. Characterization of the risk to human health of pathogenic Escherichia coli isolates from chicken carcasses. J Food Protect 1999; 62:741- 6.

16. Kariuki S, Gilks CF, Kimari J, Muyodi J, Waiyaki P, Hart CA. Plasmid diversity of multi-drug resistant Escherichia coli isolated from children with diarrhoea in a poultry-farming area in Kenya. Ann Trop Med Parasitol 1997; 91: 87- 94.

17. Nijsten R, London N, Van den Bogaard A, Stobberingh E. Invivo transfer of resistance plasmids in rat, human or pig derived intestinal flora using a rat model. J Antimicrob Chemother 1995; 36: 975-985.

18. Committee of the susceptibility bellowing to the French Society of Microbiology. (CA/SFM) 2014. Recommandations 2014. Retrieved on April 23, 2016 from SFM Website: http://www. sfmmicrobiologie.org/

19. Magiorakos AP, A. Srinivasan, Carey RB, Carmeli Y, Falagas ME, Giske CG, Harbarth S, Hindler JF, Kahlmeter G, Olsson-Liljequist B, Paterson DL, Rice LB, Stelling J, Struelens MJ, Vatopoulos A, Weber JT, Monnet DL. Multidrug-resistant, extensively drugresistant and pandrug-resistant bacteria: an international expert proposal for interim standard definitions for acquired resistance. Clin Microbiol Infect 2012; 18: 268-281.

20. Chopra I. New developments in tetracycline antibiotics: glycylcyclines and tetracycline efflux pump inhibitors. Drug Resist Updat 2002; 5(3-4):119-125.

21. Levy SB. Antibiotic resistance: consequences of inaction. Clin Infect Dis 2001; 33(Suppl. 3): 124-129.

22. Chaiba A (2011) Impact des pratiques de production de poulet de chair à Meknès sur la qualité bactériologique, I'antibiorésistances et les résidus d'antibiotiques dans les produits aviaires finis, Thèse de Doctorat National, Université Moulay Ismail, Faculté des Sciences de Meknès, Marocco.

23. El Allaoui A, Rhazi Filali F, Oumokhtar B. Prevalence and Antibiogram Study of Escherichia coli and Staphylococcus aureus in Turkey Meat in Morocco. Pharm Anal Acta 2013; 4 (9):4-9. 
24. Turtura GC, Massa S, Chazvinizadeh H. Antibiotic resistance among coliform bacteria isolated from carcasses of commercially slaughtered chickens, Intern J Food Microbiol 1990; 11:351354.

25. Bongers JH, Franssen F, Elbers AR, Tielen MJ. Antimicrobial resistance of Escherichia coli isolates from the faecal flora of veterinarians with different professional specialties. Vet Quarterly 1995; 17:146 -149.

26. Al-Ghamdi MS, El-Morsy F, Al-Mustafa ZH, Al-Ramadhan M, Hanif $M$. Antibiotic resistance of Escherichia coli isolated from poultry workers, patients and chicken in the eastern province of Saudi Arabia. Trop Med Int Health 1999; (4):278-283.
Publish in The International

Arabic Journal of Antimicrobial Agents

The Journal is an open access peer-reviewed journal that publishes scientific papers about all aspects of antimicrobials. The journal will publish original research articles, reviews, brief reports and case reports dealing with basic and clinical antibacterial agents, antiviral, antiprotozoals, antituberculuous, antifungal and antihelminthes agents. All manuscripts must be prepared in English, and are subject to a rigorous and fair peer-review process. Accepted papers will immediately appear online. The journal aims to advance the knowledge, attitude and the research of chemotherapy in the Arabic world in cooperation with international, national scientific and public societies as well as research centers with similar aims and objectives. 